\title{
Forgotten but not gone: A heuristic literature review of sibling suicide bereavement
}

Leah Jane Royden, School of Public Health \& Psychosocial Studies, Auckland University of Technology

\section{ABSTRACT}

INTRODUCTION: It is often said that Aotearoa New Zealand suffers from a "culture of silence" around suicide. The sibling experience, it seems, forms a silence within that silence. Suicidebereaved siblings face what has been termed a "double loss." Their sibling is gone, and so is their family as they knew it. Typically, they mourn both losses in isolation, the "forgotten bereaved." Although Aotearoa New Zealand's suicide rates are amongst the highest in the developed world, there are currently no academic papers dedicated exclusively to the sibling experience of suicide loss. This has serious implications, as suicide-bereaved siblings experience significantly higher rates of mental illness compared to control groups even when pre-existing psychopathology, health problems, and social disadvantages are taken into consideration. In addition, their own risk of suicide has been found to double.

METHOD: This heuristic literature review aims to clarify and summarise what research focused on the sibling experience of suicide bereavement has highlighted so far, drawing on the author's lived experience to examine key themes of guilt, "unacceptable" anger, social stigmatisation, self-judgement, isolation, and the shattering of relational trust.

FINDINGS AND IMPLICATIONS: Siblings cannot be expected to "seek" help, it needs to be offered-strongly and repeatedly. With this in mind, potential implications for mental health practice with suicide-bereaved siblings will be discussed, as well as broader social initiatives and areas in need of future research.

KEYWORDS: Sibling suicide; suicide bereavement; suicide survivors; sibling loss; bereaved by suicide

\section{Background}

\section{The silent scream}

Aotearoa New Zealand's suicide rates are high by international standards, and continue to climb unabated. Last year, 654 people took their own lives, and every tragically premature loss carves ripples of grief across families, peer groups and communities (Coronial Services of New Zealand, 2020). With the birth rate between 1960 and 2018 averaging 2.39 children per woman (Statistics New Zealand, 2019), each death typically represents at least one living sibling left behind.

It was not until I became one of their number-a number left unrecorded, unacknowledged - that I was able to truly understand what suicide bereavement looked and felt like beyond the statistics, anecdotes, and clichés. My brother was
AOTEAROA

NEW ZEALAND SOCIAL WORK 33(2), 19-31.

CORRESPONDENCE TO: Leah Jane Royden leah.royden@gmail.com 
one of 540 people whose deaths were ruled self-inflicted that year, a rate of 12.2 per 100,000 , making me one of over a thousand siblings struggling to make sense of what felt unbearably senseless. In literature, those that experience the loss of a loved one to suicide are termed "survivors," a label that serves to acknowledge the trauma inherent in the experience, and I can think of no label more accurate (Rakic, 1992). As I wrote (anonymously) in the New Zealand Herald ("A Sister's Tale," 2011), in an attempt to enlighten those as blissfully unaware, as I had once been:

They cross the road when they see my mother coming. The neighbours shuffle quickly back inside, as though scared it might be contagious. A hundred bunches of flowers are turning slowly brown inside the house, but the phone stays stubbornly silent. The men talk to my father of rugby. Fishing. Boating. Work. Anything but what has happened ... his very name is enough to kill conversation stone dead, and make everyone look pointedly at their watches. Often, they suddenly remember they have somewhere else to be.

Yes, Aotearoa New Zealand has a "culture of silence" around suicide, to use the commonly touted media phrase. But both my lived experience and the research literature points to a silence within that silence: sibling suicide bereavement.

When I want to understand a thing, I read about it. I research, I absorb, I immerse myself, I dig and dig until I can make some sort of sense of it. I think I always knew I was never truly going to understand why my brother took his own life. But I also knew I had to try, or lose myself completely to the emotional maelstrom gathering dark and sinister around me. Why did he die ... and why do I feel like this? I never imagined I would feel like this. Why can't I feel anything at all except rage? Why can't I cry? Why can't I recognise myself in the mirror anymore?
So, I started digging. It began at my GP's office, with a dog-eared card for a local support group I was ultimately too isolated and afraid to call. Piles of library books (including one full of real suicide notes) left me feeling a strange mix of confused, distant, and frustrated. I could find nothing specifically written for siblings, even as I watched the stack of tomes for bereaved parents grow taller by my mother's bedside. Occasionally I would flick through them, and feel even more alone and freakish in my experience. Nothing resonated, and each page made me feel sadder and sicker and more shameful about my feelings, which none of my family (or indeed, anybody who had lived through this) seemed to share. My Google search history that year must make for curious, if morbid reading: "brother suicide angry"; " sibling suicide normal feelings"; "why do people kill themselves?"; "is suicide weak?"; "suicide when do I feel normal again?" But no matter where I looked, I could not find anything that spoke to siblings. I could not find myself.

Ten years later, I was planning my dissertation as a training psychotherapist, picking my brains for a suitable research topic.

"What you need to do," my supervisor advised me, "is find the gap in the research. What's an angle nobody has taken in your area of interest?" The words came to me seemingly unbidden, bubbling up involuntarily from somewhere deep in my chest: "I want to research sibling suicide."

"Right then," he said briskly, "let's have a look at what's already out there." He punched the keyboard, hit Enter, and scrolled. And scrolled. And frowned.

In academia, I had gained access to a world of information that was not open to me as a newly bereaved sibling. But as it turned out, this new world was almost as bereft of the sibling experience as my local library was all those years ago. Eventually, my searches turned up some seemingly relevant 
manuscripts, but I was disheartened to discover study after study on "family suicide bereavement" lacked any meaningful inclusion of siblings whatsoever, or relied on secondhand accounts (usually from parents) to draw conclusions (Feigelman et al., 2009; Gall et al., 2014; Jordan, 2009; Lindqvist et al., 2008; Miers et al., 2012; Sandler et al., 2016; Wood et al., 2012). Similarly, articles on "sibling bereavement" tended to touch briefly on the experience of suicide loss at best, and I found the material frustratingly vague and broad.

It is a curious thing, that something affecting so many should be so invisible. I once asked a Psychology Today editor if I could write a column on sibling suicide. The reply: "Sorry, but that's a bit too niche. Could you just write one on grief generally?" I scrolled through the list of categories listed on Psychology Today in angry disbelief. There were tags for face blindness, the Keto diet, ghosting, memes, the Goldwater rule.

Is sibling suicide a niche topic?

In numbers impacted, no.

In perception? Apparently.

\section{Methodology}

\section{Finding my voice}

After many hours and many search combinations across numerous academic databases, I finally managed to find research related directly to suicide-bereaved siblings. Papers that, in some cases, spoke to me so deeply I found myself longing to reach through the words and touch the people who spoke them. But there were just nine of them. Nine papers, spanning all the way back to 1970. Of the nine, three were doctoral dissertations and one a Master's thesis, each compiled by researchers who had previously noticed the same absence of the sibling experience that I had stumbled across.

Like most populations impacted by trauma, sibling suicide survivors present ethical research challenges. Qualitative studies must generally exclude interviewees seen as mentally fragile, and avoid going into too much depth to prevent re-traumatisation (Powell \& Matthys, 2013). This unavoidably cuts out a vast swathe of people whose experience may be vitally important, but cannot be safely examined. Some studies have attempted to circumvent this by getting one stable person in the family to report on the others. However, sibling suicide survivors do not typically tell their families how they really feel (Powell \& Matthys, 2013; White, 2012).

Therefore, in an attempt to more clearly illuminate the sibling experience in an ethically permissible manner, I decided to engage in a systematic process of heuristic inquiry, examining what made it possible for me to put words to the experience of my brother's death. Since I would have likely been ruled too psychologically unwell following my own bereavement to take part in any of the studies I examined, I hoped to offer some deeper insight into the traumatic impact of sibling suicide. After all, what can truly be known about a psychologically debilitating event if one is prevented from studying the psychologically debilitated?

As a containing aspect, I seeded my heuristic exploration with academic literature focused on sibling suicide survivors. I began by conducting a literature review, reporting my findings from historical and current research on sibling loss generally, before turning my focus to suicide bereavement. Including only papers solely dedicated to the sibling experience of loss left me with frustratingly little source material, but it felt like a vital restriction. Siblings appeared so absent, so buried, so easily lost in more general studies in a way that seemed uncannily similar to what happens to them in the aftermath of a suicide. I would focus on siblings, and only siblings, in an attempt to avoid adding to this dynamic.

I drew key themes from my meagre pile of literature, including conflicting perspectives, in an attempt to gain an 
overall picture of what has been written about the sibling experience of suicide. I then turned my attention to my own experience of attempting to put words to the loss of my brother in a sustained process of heuristic enquiry, a reflexive approach in which I served as both subject and researcher. Spanning the better part of a year, this process was supported by ongoing examination and cataloguing of my thoughts, feelings, realisations and memories in response to the literature.

Through a process of sustained immersion, self-dialogue and self-discovery, I hoped to capture something of the essence of sibling suicide bereavement. Whatever I uncovered would inevitably be seen through the lens of my personal experiencing, but would likely include themes and meanings that have a universal element to them (Moustakas, 1990).

\section{Findings}

\section{Even silence has a sound}

Numerous researchers have referred to siblings as the "forgotten bereaved" in grief studies (Bolton et al., 2016; Dyregrov \& Dyregrov, 2005; Fletcher et al., 2015; Haugen et al., 2016; Pettersen et al., 2013; Powell \& Matthys, 2013; Rakic, 1992; Rappaport, 1994; Rostila et al., 2013; Rostila et al., 2017; Todd, 1980; White, 2012). Recorded sibling suicide research dates back only four decades, and just nine pieces of research have been dedicated exclusively to the sibling experience of suicide bereavement.

\section{Research summary:}

1. The oldest manuscript on sibling suicide, a qualitative study of the long-term effects based on taped interviews, was a doctoral dissertation focusing on 10 US siblings who were aged between 19 and 24 at the time of losing their brother or sister (Todd, 1980).

2. Twelve years later, in 1992, a second piece of doctoral research was written based around interviews with eight people who had lost a sibling-some to suicide, and some to illness-in an attempt to elucidate the unique impact of self-inflicted death on siblings (Rakic, 1992). The study also utilised the Rorschach test in an attempt to highlight unconscious emotional disturbance.

3. In 1993, Brent et al. carried out psychiatric assessments on 25 adolescent sibling suicide survivors and compared the results to those of 25 demographically matched control participants.

4. A year later, in 1994, Rappaport wrote about her experiences of psychoanalytic work with two female sibling survivors, each painfully conflicted about whether or not to bear children in light of their traumatic loss.

5. Another 12 years passed until the next study, in which Norwegian researchers Dyregrov and Dyregrov (2005) used questionnaires to explore the psychosocial situation of 70 suicidebereaved siblings, including their psychological state, support networks, and experiences with mental health professionals.

6. Seven years later, White (2012) carried out a phenomenological study for her doctoral research that pinpointed and examined central themes in interviews with 15 US siblings bereaved by suicide.

7. Three further studies were then published in 2013. The first investigated the multiple ways in which siblings bereaved by suicide experience and manage uncertainty and loss. The study included 45 siblings, each interviewed in depth for qualitative analysis (Powell \& Matthys).

8. The second 2013 study examined a national data register in Sweden (which included 13,693 sibling suicide 
survivors) in search of a correlation between sibling suicide and early mortality (Rostila et al.).

9. The third and final 2013 paper examined 18 suicide-bereaved siblings' perceptions of health services, including their reasons for seeking (or not seeking) support, and their personal recommendations to healthcare professionals working with suicidebereaved siblings (Pettersen et al.).

10. My own piece of research, completed in 2018, was the tenth (Royden, 2018).

The following sections detail what has been uncovered so far about the sibling experience of suicide bereavement. While individual sibling responses vary greatly depending on the situational and relational context of the loss, a number of key themes emerged from both the existing literature and my heuristic exploration of the research.

\section{Psychological impact}

\section{"Who am I without you?"}

In addition to the painful grief of "normal" loss, those who lose a brother or sister to suicide have been found to experience a range of uniquely challenging phenomena. Sibling suicide survivors are at particular risk of developing complicated grief reactions, depression, and post-traumatic stress symptoms (Brent et al., 1993; Dyregrov \& Dyregrov, 2005; Pettersen et al., 2013; Rakic, 1992; Rostila et al., 2013; White, 2012). Common emotional responses include intense anger and guilt, a pervasive sense of responsibility for the death, and feelings of shame, worthlessness, anxiety, and fear (Brent et al., 1993; Rakic, 1992; Rappaport, 1994; Royden, 2018; Todd, 1980; White, 2012). It is also common for survivors to feel relief if the death marks the end of a long period of worry and uncertainty. This tends to fuel further guilt, creating an ongoing cycle of emotional disturbance (White, 2012).
Siblings often report feeling significant guilt, and research indicates that this can happen for a variety of reasons. Some siblings may have kept potentially deadly secrets about their brother or sister, for example, the occurrence of previous suicide attempts and/ or self-destructive behaviour (Dyregrov \& Dyregrov, 2005; Rakic, 1992). Many felt they did not do enough to stop the suicide or berated themselves for failing to notice their sibling was depressed. The majority reported experiencing particularly strong guilt reactions when they began to resume their lives (Powell \& Matthys, 2013; White, 2012). In addition to what was overtly revealed by her interview subjects, Rakic (1992) noted signs of suppressed guilt, and felt it had such a pervasive hold on some siblings that, at an unconscious level, they believed they no longer deserved to have joy, happiness, or success in their lives. This was a realisation I eventually came to in my own therapeutic work (Royden, 2018). Rappaport (1994) made similar observations, conceptualising the drive to self-sabotage as a form of self-punishment. It is worth noting that feelings of guilt were not significant in Rakic's control group of siblings bereaved by illness (1992).

Another emotional phenomenon that warrants further discussion is the anger commonly experienced by sibling suicide survivors, which is typically uncomfortable and shameful for them (Powell \& Matthys, 2013; Rakic, 1992; Rostila et al., 2013; Royden, 2018; White, 2012). White (2012) draws parallels with the murder of a family member, pointing out how much hatred is typically felt towards the killer and, in the case of suicide, the dead loved one is both victim and perpetrator. Anger is also thought to stem from deep and painful feelings of rejection and abandonment (Rakic, 1992; Rostila et al., 2013; Royden, 2018). However, the presence of anger or rage (let alone the expression of such emotions) is usually viewed as highly inappropriate and unacceptable, even in families that can speak relatively freely about emotions (Rakic, 1992; 
Royden, 2018). Unable to be processed or borne, anger may then be repressed, turned inwards as self-punishment, or redirected as impulsive lashing out-all of which can serve to block resolution and acceptance of the loss (Rakic, 1992).

\section{Family dynamics}

\section{"You've got to be strong for your parents now."}

No clear picture of a "typical" reaction to sibling suicide can be drawn from the literature, but strong consensus exists about what tends to happen in the wider family structure: each person becomes too preoccupied with their own pain to offer meaningful support to the others (Brent et al., 1993; Dyregrov \& Dyregrov, 2005; Pettersen et al., 2013; Powell \& Matthys, 2013; Rakic, 1992; Rappaport, 1994; Rostila et al., 2013; Royden, 2018; Todd, 1980; White, 2012). Suicide-bereaved brothers and sisters often find themselves "not only neglected, but expected to put their needs aside in order to spare their parents further distress" (Rakic, 1992, p. 2). Siblings usually experience a desperate desire to make their parents happy again, and they tend to be instructed implicitly, explicitly, and repeatedly by others to "stay strong" for them (Powell \& Matthys, 2013; Royden, 2018; White, 2012). Many, therefore, try to appear "emotionally together" or even cheerful around their family, despite their intense pain. The siblings' demeanour is then perceived as evidence that they have not been badly affected by the loss, making them less likely to receive the support and care they crave (Dyregrov \& Dyregrov, 2005; Rakic, 1992).

Unsurprisingly, siblings still living in the family home tend to report the highest levels of psychic distress in response to the loss (Dyregrov \& Dyregrov, 2005; Rostila et al., 2013; White, 2012). These siblings may be required to take on the role the deceased fulfilled within the family (Powell \& Matthys, 2013; White, 2012) or "parent" their grief-crippled mothers and fathers (Dyregrov \& Dyregrov, 2005; Powell \& Matthys, 2013;

Rakic, 1992; Todd, 1980; White, 2012). In short, survivors of sibling suicide suffer from what has been termed a "double loss": their sibling is gone, and so is their family as they knew it. Typically, they mourn both losses in isolation (Powell \& Matthys, 2013; Royden, 2018).

\section{Social stigma}

\section{"Did you hear her brother killed himself?"}

The sense of utter isolation siblings experience is exacerbated to varying degrees by the social stigma around suicide, which makes discussing the death with people outside the family challenging (Powell \& Matthys, 2013; Rakic, 1992; Rostila et al., 2013; Royden, 2018; Todd, 1980). Historically, surviving family members of a self-inflicted death were actively shunned by society, considered tainted by the "sinful" action of the deceased's "self-murder" (Rakic, 1992; Todd, 1980; White, 2012). Such open hostility may be rare today, and a clear shift can be observed in the language used around suicide in the academic literature over time. However, research shows that stigmatising attitudes and behaviours remain common, if more covert. Suicide-bereaved families tend to receive less community support compared to families that lose a member to "natural" causes (Rostila et al., 2013). They may be avoided and/or blamed for the death by others, and it's not uncommon for the deceased to be disparaged as "selfish" and "cowardly" for their actions (Powell \& Matthys, 2013).

\section{Self-stigmatisation}

\section{“I can't escape myself ... but I can spare you, at least."}

Many siblings describe being extremely hurt by the actions of those they hoped would support them following the suicide (Powell \& Matthys, 2013; Rakic, 1992; 
Royden, 2018; White, 2012). Some spoke of friends abandoning them altogether, while others recall people acting as though the death never occurred, silencing them with platitudes, or telling them they should not feel the way they do about the loss (Rakic, 1992; Royden, 2018; White, 2012). This typically occurred against a backdrop of deep longing and need for the siblings to have their grief heard and validated (Powell \& Matthys, 2013; Royden, 2018; White, 2012). However, the relational dynamics surrounding sibling suicide survivors appear complex. During interviews, some brothers and sisters spoke of friendships ending due to impatience that they are "still not over it," but others admitted to deliberately withdrawing from their friends due to experiencing them as immature, unempathetic and / or focused on trivial concerns (Dyregrov \& Dyregrov, 2005). Rostila et al. (2013) additionally point out that survivors are likely to stigmatise themselves negatively due to guilt, and therefore self-isolate out of shame. Rakic (1992) and White (2012) both posit that survivors' perceptions of stigmatisation can be more often related to intrapsychic processes than actual acts of rejection. Siblings often swallow their hurt to avoid awkwardness with their peers, leading them to feel "lonely in a crowd." This may contribute to an overall sense that others are rejecting or avoidant.

Whatever factors are at play, the lack of accessible support for siblings represents a significant obstacle on the road to accepting and mourning their loss (Rakic, 1992; White, 2012). In my own research, as I explored what made it possible to talk about a sibling's suicide, I devised an "equation" for the process of disclosure:

It is possible to put words to the experience of sibling suicide when the fear of - and potential for-relational pain is outweighed by the desire forand potential for-relational connection. (Royden, 2018, p. 65)
This mirrors the core belief of relational psychotherapy: the need for the human psyche to keep relationships intact, even at the cost of the self (Perlman \& Frankel, 2009). However, it also captures the desperate longing for relief from psychic aloneness evoked by trauma (van der Kolk, 2014).

\section{Relationships and repetition}

\section{"Everyone I love leaves in the end."}

Research indicates that sibling suicide has significant, lasting effects on the emotional and relational lives of survivors. Some older siblings felt they had re-lived their lost sibling relationship with their romantic partners, entering unsatisfying or painful pairings which ultimately resulted in their being abandoned or let down again (Todd, 1980; Royden, 2018; White, 2012). Rakic (1992) wrote of the potential for a sibling's suicide to severely damage any sense of trust in the stability of meaningful relationships, while Todd (1980) pointed out that, in her study, the siblings who carried the most guilt around the suicide typically engaged in the most selfdestructive romantic pairings (Todd, 1980). Many siblings became preoccupied with the fear of losing other loved ones to death or being abandoned by them and worry that the tragedy of suicide will be repeated in their own future families (Rappaport, 1994; Royden, 2018; Todd, 1980; White, 2012).

Todd (1980) additionally described a deep sense of "maternal inadequacy" amongst some of the female siblings she interviewed, and Rappaport (1994) described her clinical experiences of working with two such young women. Both of them longed to become mothers, but could not bear to do so until they had worked through their deeply conflicted and painful feelings about the loss in therapy. In my heuristic exploration of sibling suicide, I admitted and explored my own deep ambivalence around motherhood, including my fear that the trauma of suicide bereavement has damaged my ability to parent beyond repair (Royden, 2018). 


\section{The question of why}

\section{"The one person who knows is the one person I can never ask."}

Suicide challenges fundamental notions of self-preservation, and nearly all survivors struggle for varying lengths of time to make sense of what happened and why (Rakic, 1992; Rappaport, 1994; Rostila et al., 2013; Royden, 2018; White, 2012). Several studies have shown a correlation between sibling bonds which included dual relationships (for example, one sibling acting as a "parent" for another) and more intense, lengthy grief responses (Rakic, 1992; Rappaport, 1994; Todd, 1980; White, 2012). Many siblings do report eventually making peace with the fact that unanswered questions will always remain (White, 2012). However, Powell and Matthys question the validity of "acceptance" as the end stage of grief, arguing instead that mourning a suicide is a dynamic process that evolves throughout the life stages (2013).

\section{Supportive experiences}

\section{"You mean it's not just me?"}

Support groups were named repeatedly in the literature as a helpful resource for siblings (Pettersen et al., 2013; Powell \& Matthys, 2013; Rakic, 1992; Rostila et al., 2013; White, 2012). Clinicians working with survivors of sibling suicide are advised that, in many cases, simple reassurances that their grief reactions are "normal" can be extremely soothing (Powell \& Matthys, 2013; Rakic, 1992; White, 2012). Additional recommendations to mental health workers include leveraging positive memories of the deceased to lessen focus on the traumatic nature of their death, while working to re-direct anger and reduce guilt (Powell \& Matthys, 2013; White, 2012). Research further suggests that the remaining relationships within the family should be carefully considered, and clinicians should be proactive about providing practical guidance and resources (Dyregrov \& Dyregrov, 2005;
Rostila et al., 2013). Pettersen et al. (2013) warned that clinicians may have to work particularly hard to foster trust with siblings who feel their brother or sister received inadequate mental health care prior to their death. They further posit that the siblings who report the greatest difficulties in seeking help may well be those who need it most.

\section{Post-traumatic growth}

\section{“It's not a silver lining. But it's not nothing either."}

Surprisingly, some researchers described positive outcomes that can ultimately be derived from the experience of surviving a sibling's suicide. During interviews, a number of survivors spoke of experiencing noticeable personal growth and a profound shift in perspective (Dyregrov \& Dyregrov, 2005; Powell \& Matthys, 2013; Rakic, 1992; White, 2012). Many became involved in suicide prevention activities, and valued the increased compassion and empathy their life experiences had imbued them with (Powell \& Matthys, 2013). It is poignant that sibling survivors of suicide often find a renewed sense of purpose and meaning in their lives, as they face an elevated mortality rate from all causes (Rostila et al., 2013). Brothers are most likely to die prematurely in the first year of bereavement, while sisters are at highest risk $2-5$ years post-loss (particularly from cardiovascular disease). Additionally, as was long suspected but difficult to prove (Brent et al., 1993), sibling survivors of suicide appear to be at an increased risk of taking their own lives. Rostila et al. (2013) indicated that the risk of suicide roughly doubles.

\section{Discussion and recommendations}

\section{Better silent than silenced}

Sibling suicide survivors are an atrisk demographic across a wide spectrum of adverse health and social outcomes-everything from depression to cardiovascular disease. Most concerningly, 
they are at elevated risk of taking their own lives, causing suffering to snowball within families, peer groups, and communities. Brothers and sisters who lose a sibling to suicide are both vulnerable and easily identifiable given the need for self-inflicted deaths to be thoroughly investigated and recorded, yet there appear to be no dedicated resources available to them-and certainly no targeted support.

Currently, siblings are left to seek assistance of their own volition, with scattered community groups and online forums generally their only options unless they can afford private counselling. This contrasts starkly with, for example, Australia's StandBy suicide postvention programme, which offers targeted funded support for people bereaved by suicide-everything from printed resources to support with funeral planning to specialised counselling (www.standbysupport.com.au).

The existing literature on sibling suicide bereavement, my heuristic exploration, and my lived experience (paired with my clinical knowledge as a psychotherapist) suggest a number of recommendations that may assist suicide-bereaved siblings in Aotearoa New Zealand.

\section{Social initiatives}

\section{Readily available information}

Given the differing needs of suicidebereaved siblings comparative to other family members, dedicated resources could be extremely helpful.

Research indicates that simple normalising of what siblings feel can be incredibly soothing, but currently most resources around sibling suicide are hidden behind academic paywalls - which could be seen as a collusion with societal silencing. Given the scarcity of such work, there are ethical questions around the continuation of this practice, and a case for constructing a publicly accessible repository of such documents (for example, establishing a dedicated website for suicide-bereaved siblings and / or developing and distributing printed resources). My decision to submit this piece of research to an open-access journal forms a small but significant act of resistance against this status quo.

In addition, I believe that other family members could benefit from learning about how siblings tend to process such a loss. Perhaps it could help families begin to allow some space for siblings' different (but no less valid) grief experiences.

\section{Dedicated support groups}

Support groups were repeatedly named in the literature as a positive resource for many siblings. However, little detail was given about the groups referenced in the research. It is not clear whether they were open to any bereaved person, restricted to people impacted by suicide, or created exclusively for those who have lost a sibling to suicide. A number of open suicide bereavement groups currently operate in Aotearoa New Zealand, but further investigation would be needed in order to make specific recommendations.

I did not attend any groups following my own bereavement, and therefore cannot contribute any insight from my own lived experience. However, I question how freely siblings would be able to speak in an open suicide bereavement group that included a diverse range of relationships and roles. The open suicide bereavement groups currently available in Aotearoa New Zealand (despite the profoundly important work they do) are not spaces created with the unique needs of siblings in mind, and research has shown that siblings generally feel their grief to be less important comparative to their parents' (a message they tend to receive both implicitly and openly).

In addition, many siblings struggle with intense anger about the death, and open 
expression of siblings' anger (as discussed at length in the literature) tends to be absolutely unacceptable within the wider family. As I wrote in my journal while completing this piece of work, "To try to speak in front of other parents [in a group] would mean doing it with the spectre of Mum and Dad in the room, and I cannot imagine that being possible" (Royden, 2018, p. 83). In my view, the literature strongly suggests that dedicated, sibling-only suicide bereavement support groups could be powerfully therapeutic.

\section{Targeted support}

Research indicates that the most desperate need for mental health assistance may well be experienced by the siblings who have the most powerful internal barriers to seeking it out. Siblings are generally compelled to deny the impact of their loss in their families and social relationships, and therefore they may well also deny it to themselves and/or any mental health workers tasked with assisting them. Further compounding the problem, if siblings feel their brother or sister was failed by mental health services, they are likely to be negative and / or hostile towards the idea of engaging with such services themselves.

I would also like to point out that it seems, albeit anecdotally, that many siblings do not seek mental health assistance for their loss. During my own training, I read a number of case studies in which, frustratingly, a sibling's suicide was mentioned almost as a footnote, behind the "presenting issue" of self-harm, or depression, or dysfunctional anger (my own reason for engaging in therapy). Reading about the struggles of these clients through the lens of my own experiencing, it felt painfully obvious to me how huge the suicide likely loomed in their psyche. There may be a tendency for siblings to downplay and deny the impact of their brother or sister's death, or simply lack awareness of how such a loss relates to the symptom/s causing their current distress.
In short, siblings cannot be expected to "seek" help, it needs to be offered-strongly and repeatedly.

\section{Implications for practice}

\section{Family support}

In my view, mental health practitioners who work with suicide-bereaved families will benefit from remaining mindful of the pressure on siblings. Research indicates that what siblings speak on the surface may not be the words they wish to say and, while siblings long to be understood by their families, the risks attached to doing so can feel immense. I believe this reflects a dynamic of risk versus reward, with family therapy positioned in the space of high potential reward (feeling known and accepted by other family members), but also heightened risk (feeling rejected, unseen or wrong, even in a therapeutic environment). Mental health practitioners working in this space may also need to think about how to manage potential impasses in family therapy. Parents' acknowledgement of the sibling experience may be too much to hope for given the catastrophic loss they are trying to process themselves. On the other hand, the pain of siblings in the face of this disavowal can be palpably raw.

\section{Individual therapeutic work}

In order to prepare practitioners for working effectively with clients who have lost a sibling to suicide, research suggests that a more nuanced and differentiated understanding of suicide bereavement is necessary. The sibling experience differs greatly from how parents, children and spouses grieve, and it is hidden-potentially denied even to the self.

Research suggests that important factors to consider are:

1. Acknowledging loss of identity as a core part of the grief process of sibling suicide. 
2. Respecting the sibling's defences, and not dismantling them before building a foundation of safety.

3. Being mindful of re-creating a dynamic in which the sibling feels like they need to protect or reassure.

On the basis of my own research and lived experience, I additionally wish to encourage practitioners to be aware of their own internalised systems of silencing. What occurs at a societal level tends to be reproduced in the self, and each of us has a lifetime of conditioning urging us on a visceral level to recoil from the issue of suicide. Traces are likely to remain despite our decision to work in the helping professions. However, what a mental health practitioner offers by resisting that ingrained response is valuable beyond measure, and what is risked by giving in potentially devastating.

As I wrote in my journal while completing this piece of work, I described the therapy room as the only place it felt safe to speak freely. I also pointed out how shattering it would be to experience feeling rejected or judged in that space. Therapy was a safe space I regrettably could not find "out there" in the world and had to purchase, a place to bring all that I could not say to anybody else. The literature suggests other siblings have a similar experience, being familiar with internal, family, social and societal messages that their experience is unacceptable to others.

Within a therapeutic setting, my desire to speak and to be known could take place almost entirely free from fear. However, I can only speculate-with concernwhat potential for harm exists if that sense of safety collapses. What if instead of empathy, warmth and acceptance I was met with judgement or moralising? What if I felt the need to reassure my therapist, visibly disturbed by my words? Any threat to my ability to speak freely was highly anxiety provoking for me. Reflecting on my experiences, I wonder how often my therapist may have felt the urge to direct me, or advise me, or encourage me to "move on". I know how tempting it might have been, and how devastating I would have found such well-meaning statements. (Royden, 2018, p. 79)

Creating a space in which siblings can safely speak about their experience should be a practitioner's first and most important priority in my view, irrespective of their particular mental health role or therapeutic modality.

\section{Areas for future research}

More research is needed across every facet of the experience of sibling suicide, as much of what has been found has already dated almost beyond usefulness. Broadly, this heuristic literature review invites further exploration to differentiate experiences of sibling suicide survivors across cultures and gender identities. Māori and youth perspectives in particular are incredibly important to illuminate, and given the possibility for a sibling's suicide to distort the capacity for stable relational attachment, it may also be useful to track siblings' significant relationships over time.

The scarcity of information available to the general public, mirrored within the academic community, raises additional questions around how and why such an absence endures. What (and who) within the dominant discourse benefits?

There are still more questions about the "forgotten bereaved" than answers.

\section{Conclusion}

\section{Don't forget to remember}

The current body of research appears to demonstrate what often plays out in reality 
following a suicide: siblings remain unseen relative to those whose pain is considered to be more intense and in greater need of attention. Suicide-bereaved siblings typically carry their experience in quiet, desperate isolation, and repetition of (or possibly even collusion with) this silence seems to be recreated at all levels, including the world of research. What other private agonies, borne unseen and unheard, may need further inspection due to similar factors at play? Does the individual's silence influence society's perception of their experience (they do not ask, and therefore they do not need)? Or does the prevailing social climate dictate the individual's ability to speak (they should not need, they are "only" siblings)? Could there be an overarching refusal to hear, a collective denial (it is too painful to see the need)? As I write, I wonder whether this manuscript, too, will be lost to time ... buried deep beneath the needs of other groups impacted by suicide, for another like me to uncover one day and attempt to illuminate just as futilely.

Sibling survivors of suicide may be forgotten, but we are not gone. We show up in numerous adverse health statistics, we weigh our agony quietly in therapy rooms all over the world, we walk the jagged razor edge between longing to be heard and fearing minimisation, rejection, or abandonment. We grieve the loss of a relationship that all but defies definition, one we imagined would last the entirety of our lives.

I ask you, as one amongst our number, to not only listen carefully for our voices, but to answer. To answer with the compassion and thoughtfulness we tend to not know we need, but will struggle to survive without.

Accepted 17 May 2021

Published 1 September 2021

\section{References}

A sister's tale: What happens when a family member ends it all. (2011, August 3). New Zealand Herald. https://www.nzherald.co.nz/nz/news/article.cfm?c_ id $=1$ \&objectid $=10742554$
Bolton, J. M., Katz, L. Y., Sareen, J., Chateau, D., Martens, P. J., Au, W., Walld, R., Leslie, W. D., Enns, J., \& Logsetty, S. (2016). Bereavement after sibling death: A population-based longitudinal case-control study. World Psychiatry, 15(1), 59-66. doi: 10.1002/wps.20293

Brent, D. A., Perperb, J. A., Moritz, G., Liotus, L., Schweers, J., Roth, C., Balach, L., \& Allman, C. (1993). Psychiatric impact of the loss of an adolescent sibling to suicide. Journal of Affective Disorders, 28(4), 249-256. doi:10.1016/0165-0327(93)90060-W

Coronial Services of New Zealand (2020). Annual provisional suicide statistics for deaths reported to the Coroner between 1 July 2007 and 30 June 2020. https:// coronialservices.justice.govt.nz/assets/ Documents/Publications/2020-Annual-ProvisionalSuicide-Statistics.pdf

Dyregrov, K., \& Dyregrov, A. (2005). Siblings after suicide - "the forgotten bereaved". Suicide and LifeThreatening Behavior, 35(6), 714-724. doi:10.1521/ suli.2005.35.6.714

Feigelman, W., Gorman, B. S., \& Jordan, J. R. (2009). Stigmatization and suicide bereavement. Death Studies, 33(7), 591-608.

Fletcher, J., Mailick, M., Song, J., \& Wolfe, B. (2015). A sibling death in the family: Common and consequential. Demography, 50(3), 803-826. doi:10.1007/s13524-0120162-4

Gall, T. L., Henneberry, J., Eyre, M. (2014). Two perspectives on the needs of individuals bereaved by suicide. Death Studies, 38(7), 430-437. doi:10.1080/07481187.2013. 772928

Haugen, A. E., Cookman, M. L., King, A R., \& Preszler, J. R. (2016). Sibling death and adult maladjustment indices: A brief report. Journal of Loss and Trauma, 21(4), 265-274. doi:10.1080/15325024.2015.1048152

Jordan, J. R. (2009). After suicide: Clinical work with survivors. Grief Matters: The Australian Journal of Grief and Bereavement, 12(1), 4-9.

Lindqvist, P., Johansson, L., \& Karlsson, U. (2008). In the aftermath of teenage suicide: A qualitative study of the psychosocial consequences for the surviving family members. BMC Psychiatry, 8(1), 26. https:// bmcpsychiatry.biomedcentral.com/articles/10.1186/1471244X-8-26

Miers, D., Abbott, D., \& Springer, P. R. (2012). A phenomenological study of family needs following the suicide of a teenager. Death Studies, 36(2), 118-133. do i:10.1080/07481187.2011.553341

Moustakas, C. (1990). Heuristic research: design, methodology, and applications [Sage Ebooks version]. http://www.autonline.ac.nz/

Perlman F., \& Frankel, J. (2009). Relational psychoanalysis: A review. Psychoanalytic Social Work, 16(2), 105-125. doi:10.1080/15228870903200277

Pettersen, R., Omerov, P., Steineck, G., Dyregrov, A., Titelman, D., Dyregrov, K., \& Nyberg, U. (2013). Suicidebereaved siblings' perception of health services. Death Studies, 39(6), 323-331. doi:10.1080/07481187.2014. 946624

Powell, K. A., \& Matthys, A. (2013). Effects of suicide on siblings: Uncertainty and the grief process. Journal of Family Communication, 13(4), 321-339. doi:10.1080/15 267431.2013.823431 
Rakic, A. S. (1992). Sibling survivors of adolescent suicide [Unpublished doctoral dissertation]. Available from ProQuest Dissertations and Theses Full Text database. (ProQuest ID: 304032612)

Rappaport, J. (1994). Sibling suicide: Its effects on the wish for a child and on the maternal transference/ countertransference interaction. Journal of Clinical Psychoanalysis, 3(2), 241-258. http://www.pep-web.org/

Rostila, M., Berg, L., Saarela, J., Ichiro, K., \& Hjern, A. (2017). Experience of sibling death in childhood and risk of death in adulthood: A national cohort study from Sweden. American Journal of Epidemiology, 185(12), 1247-1254.

Rostila, M., Saarela, J., \& Kawachi, I. (2013). "The psychological skeleton in the closet": Mortality after a sibling's suicide. Social Psychiatry and Psychiatric Epidemiology, 49(6), 919-927. doi:10.1007/s00127-0130780-1

Royden, L. (2018). Better silent than silenced: searching for the words of sibling suicide bereavement [Master's thesis]. AUT, Auckland, New Zealand. https://aut. researchgateway.ac.nz/handle/10292/11582

Sandler, I., Tein, J., Wolchik, S., \& Ayers, T. S. (2016). The effects of the family bereavement program to reduce suicide ideation and/or attempts of parentally bereaved children six and fifteen years later. Suicide \& LifeThreatening Behavior, 46, 32-38. doi:10.1111/sltb.12256

Statistics New Zealand (2019). Parenting and fertility trends in New Zealand: 2018. https://www.stats.govt.nz/reports/ parenting-and-fertility-trends-in-new-zealand-2018

Todd, S. H. (1980). Sibling survivors of suicide: A qualitative study of the experience of adolescent siblings whose brother or sister completed suicide [Unpublished doctoral dissertation]. Available from ProQuest Dissertations and Theses Full Text database. (ProQuest ID No. 303003183)

Van der Kolk, B. (2014). The body keeps the score [Apple iBooks version]. Penguin Books.

White, K. S. (2012). Surviving the suicide of a sibling: A phenomenological study [Unpublished doctoral dissertation]. Available from ProQuest Dissertations and Theses Full Text database. (ProQuest ID No. 1439437483)

Wood, L., Byram, V., Gosling, A. S., Stokes, J. (2012). Continuing bonds after suicide bereavement in childhood. Death Studies, 36(10), 873-898. doi:10.1080/ 07481187.2011 .584025 